\title{
To Evaluate the Efficacy of Adjuncts Mouthwash along with Oral Hygiene Habits in Reduction of Peri-implant Mucositis - A Randomized Controlled Trial
}

\author{
Kousain Sehar \\ (MDS Periodontology and Implantology), BRS Dental College and Hospital, Sultanpur - Panchkula
}

DOI: https://doi.org/10.52403/ijshr.20220120

\begin{abstract}
Peri-implantitis is a site-specific condition that causes an inflammatory procedure in delicate tissues, and bone loss around an osseointegrated implants in work. The etiology of the implant infection is caused by the status of the tissue encompassing the implants, implant design, degree of roughness, outer morphology, and excessive mechanical burden. Periimplantitis can cause the loss of implant without multilateral expectation and treatment thoughts, Aim: the main aim of this study is to evaluate the efficacy of additional adjuncts (mouthwash) apart from the self administered oral health care in prevalence of peri-implantitis.
\end{abstract}

Material and Methodology: a randomized controlled trial was done in Srinagar district of Jammu and Kashmir. Specific clinics which undergo additional implant placement with the help of a professional were selected. A total of 45 subjects were selected who had undergone implant placements and were divided into three groups on the basis of type of adjunct/ mouthwash given.

Results: 45 periodontally healthy subjects were assessed for the presence of peri-implant mucositis. $100 \%$ of subjects were disease free within 12 weeks period. The prevalence of periimplantitis was found to be much reduced in group 1, followed by group 2and group 3 . Average plaque index and bleeding on probing index was also decreased in first two groups.

Conclusion: within the limits of the said study, additional use of mouthwash along with other oral hygiene practices can reduce the prevalence and severity of peri-implantitis within a week's period of time.
Keywords: Bone-Loss, Chlorohexidine, Periimplantitis, Mouthwash

\section{INTRODUCTION}

As the quantity of dental implants is consistently expanding, peri-implantitis are getting more continuous. ${ }^{1}$ The most widely recognized natural difficulty around dental implants is peri-implant mucositis, which can be found in about $64.6 \%$ of all implant patients. $^{2}$ Peri-implant mucositis is characterized as an inflammation of the peri-implant soft tissues with bleeding on probing, without the loss of bone, with or without increased probing depth and with signs of inflammation. ${ }^{3}$ Untreated periimplant mucositis can advance to periimplantitis with dynamic soft tissue and bone loss. ${ }^{4}$ Essential counteraction of periimplantitis, which contains the treatment of peri-implant mucositis, requires compelling techniques to build up and keep up sound peri-implantconditions. ${ }^{5}$ Risk indicators for peri-implant mucositis and peri-implantitis were distinguished in various clinical examinations, precise surveys, and metaanalysis. ${ }^{6}$ Common risk indicators being patients age, history and presence of periodontitis, smoking, type 1 or type 2 diabetes mellitus, keratinized mucosa width, and with absence of regular checkups. ${ }^{7}$ Relationship between peri-implantitis infections and the presence of pathogenic microorganism was demonstrated. ${ }^{8}$ Studies have indicated that inadequate oral hygiene 
and subsequent accumulation of oral biofilm may lead to peri-implant infections. ${ }^{9}$ Periimplant soft tissues develop more severe inflammatory response when presented to oral bio film and require a more extended healing phase after removal of biofilm contrasted with delicate tissues encompassing common teeth. ${ }^{10}$

Patients' age has not been unmistakably recognized as a risk indicator for peri-implantitis. ${ }^{6}$ However patients with more age, may experience issues with oral cleanliness because of diminished vision and fine motor abilities, hyposalivation, polypharmacy and lack of oral hygiene in nursing homes. ${ }^{7}$ As peri-implant mucositis can be treated by taking out plaque, sufficient mechanical plaque control is basic to forestall the progress and even development of peri-implant diseases. ${ }^{11}$

Involvement in a standard prophylaxis routine is essential in light of the fact that early recognition of soft tissue irritation around dental implants can prevent or defer the change of mucositis into periimplantitis, in this manner lowering the patient treatment costs and the weight of potential implant loss. ${ }^{12}$

The current examination doesn't explore adjuvant medicines alongside the mechanical plaque removal during proficient oral hygiene methodology however the impact of extra oral hygiene procedures at home supporting the goal of ailment. The point of the examination was to decide if the adjuvant utilization of a selfdirected plaque control altogether decreases severity and prevalence of peri-implant mucositis contrasted with no mouthwash used.

\section{MATERIAL AND METHODOLOGY}

A randomized controlled trial was done in clinics with a proper setup of implant placement by a professional in Srinagar district of Jammu and Kashmir. The study populations were adults suffering from peri-implant mucositis who were selected during oral maintenance appointments. An informed consent was signed before the inclusion of any subject in the study.

Inclusion Criteria: the subjects were selected on the basis of presence of at least one dental implant in the oral cavity for more than a year with a specific diagnosis of mucositis. Bleeding on probing should be present as a diagnostic criterion with absence of bone loss. Signs of inflammation should be present.

Exclusion Criteria: subjects who were present smokers, tobacco chewers, or alcoholic were not selected. Subjects with any underlying systemic diseases were also excluded from the study. Uses of any systemic medication including steroids or antibiotics 3 months prior to baseline were not selected.

Randomization and Blinding: the subjects were selected randomly with equal number in all the three groups. An opaque bottle containing mouthwashes were given blindly to the subjects. The examiner was totally aware about the type of the mouthwash used but the patients did not know anything about the liquid used.

Group 1: 15 subjects were given $0.2 \%$ chlorhexidine mouthwash along with other oral hygiene instructions.

Group 2: 15 subjects were given herbal mouthwash along with other oral hygiene instructions.

Group 3: included 15 subjects who were controls and were given water as mouth wash with no oral hygiene instructions.

Clinical Examination: at baseline, clinical examination was done and group 1 and 2 subjects were given basic oral hygiene instruction. The basic instruction included the brushing technique (modified Stillman), use of interdental brushes, advantages of fluoridated toothpaste and the consequences of progression of peri-implant mucositis into periimplantitis. Supra and sub mucosal debridement were done at baseline in all the subjects $(n=45)$. Patients assigned in group 3 did not receive any additional instruction along with the basic oral hygiene instructions. All patients were asked for follow up after 4, 6 and 12 weeks. These 
follow up visits included measurement of clinical parameters with no additional mechanical debridement procedures.

Only one implant was studied in the patient. Patients with more than one implant, implant with highest mucositis severity was selected for the study. Probing depth, bleeding on probing, modified gingival index for dental implants (Loe, 1967) ${ }^{13}$, modified plaque index (Mombelli, Van Oosten, Schurch, \& Land, 1987) ${ }^{14}$, and mucositis severity score were assessed in all the subjects at baseline, 4,8 and 12 weeks.

The severity of mucositis score reaches from 0-16. It was calculated on the basis of sum of modified gingival indexscore from 4 implant sites (maximum 12 sites, mGI-0-3) and the bleeding on probing positive sites (maximum 4 sites). ${ }^{15}$ All clinical measurements were performed by the same clinician and is considered as standardized in terms of pressure and visual assessment.
Statistical Analysis: all the measurement were compiled and transferred into Microsoft excel sheet. The data was then analyzed using SPSS software. Descriptive statistic was done using frequencies and percentages. Mean and standard deviation was also calculated from the said data with statistically significant value of $p<0.05$. ANOVA test was to p-value in case of gender and age for comparing the intervention groups. Logistic regression analysis was done for both primary analyses showing the pair wise contrast between the three intervention groups. The outcome was then represented using histograms.

\section{RESULTS}

Out of 45 study subjects $66.7 \%$ were males and only $33.3 \%$ were females with age ranging from $33.3 \%$ in $30-40$ years age group, $24.4 \%$ in $41-50$ years age group and $42.3 \%$ in $>51$ years age group. (Table 1 )

Table 1: Patients' Characteristic (N/\%)

\begin{tabular}{|l|c|c|c|c|c|c|c|}
\hline \multicolumn{2}{|c|}{ Characteristics } & $\begin{array}{c}\text { GROUP 1(N=15) } \\
\text { 0.2\% CHX }\end{array}$ & $\begin{array}{c}\text { GROUP 2(N=15) } \\
\text { HERBAL }\end{array}$ & $\begin{array}{c}\text { GROUP 3(N=15) } \\
\text { WATER }\end{array}$ & Total & MEAN \pm SD & P-VALUE \\
\hline \multirow{2}{*}{ Gender } & Male & $8 / 53.4 \%$ & $10 / 66.6 \%$ & $12 / 80 \%$ & $30 / 66.7 \%$ & $3.52 \pm 0.22$ & $0.000 *$ \\
\cline { 2 - 6 } & Female & $7 / 46.6 \%$ & $5 / 33.4 \%$ & $3 / 20 \%$ & $15 / 33.3 \%$ & \\
\hline \multirow{3}{*}{ Age(Years) } & $30-40$ & $2 / 13.4 \%$ & $7 / 46.6 \%$ & $6 / 40 \%$ & $15 / 33.3 \%$ & $4.11 \pm 0.17$ & $0.000 *$ \\
\cline { 2 - 6 } & $41-50$ & $3 / 20 \%$ & $3 / 20 \%$ & $5 / 33.4 \%$ & $11 / 24.4 \%$ & \\
\cline { 2 - 6 } & $>51$ & $10 / 66.6 \%$ & $5 / 33.4 \%$ & $4 / 26.6 \%$ & $19 / 42.3 \%$ & \\
\hline
\end{tabular}

$\mathrm{p}$ value derived using Anovatest for the intervention groups.

Table 2: Representing the Clinical Parameters

\begin{tabular}{|c|c|c|c|c|c|c|}
\hline Groups & $\begin{array}{c}\text { Time } \\
\text { Duration } \\
\end{array}$ & $\begin{array}{l}\text { Probing } \\
\text { Depth }\end{array}$ & $\begin{array}{l}\text { Bleeding On } \\
\text { Probing } \\
\end{array}$ & $\begin{array}{c}\text { Modified Gingival } \\
\text { Index }\end{array}$ & $\begin{array}{l}\text { Modified Plaque } \\
\text { Index }\end{array}$ & $\begin{array}{c}\text { Mucositis Severity } \\
\text { Score } \\
\end{array}$ \\
\hline \multirow{4}{*}{$\begin{array}{c}\text { Group } \\
1\end{array}$} & BASELINE & $3.3 \pm 1.02$ & $2.50 \pm 0.88$ & $1.25 \pm 0.35$ & $1.27 \pm 0.44$ & $9.08 \pm 1.78$ \\
\hline & AT4 ${ }^{\mathrm{TH}}$ WEEK & $3.2 \pm 0.22$ & $1.00 \pm 0.75$ & $0.98 \pm 0.25$ & $1.05 \pm 0.69$ & $5.30 \pm 3.33$ \\
\hline & AT6 ${ }^{\mathrm{TH}}$ WEEK & $3.3 \pm 0.18$ & $0.75 \pm 1.05$ & $0.72 \pm 0.30$ & $0.90 \pm 0.60$ & $4.54 \pm 3.75$ \\
\hline & AT12 ${ }^{\mathrm{TH}}$ WEEK & $3.2 \pm 0.10$ & $0.49 \pm 0.74$ & $0.52 \pm 0.11$ & $0.78 \pm 0.61$ & $2.11 \pm 2.21$ \\
\hline \multirow{4}{*}{$\begin{array}{c}\text { Group } \\
2\end{array}$} & BASELINE & $3.3 \pm 0.59$ & $2.15 \pm 1.01$ & $1.52 \pm 0.42$ & $1.32 \pm 0.50$ & $9.08 \pm 2.44$ \\
\hline & $\mathrm{AT}^{\mathrm{TH}}$ WEEK & $3.1 \pm 0.51$ & $1.05 \pm 1.08$ & $1.35 \pm 0.55$ & $1.05 \pm 0.40$ & $6.50 \pm 2.01$ \\
\hline & AT6 ${ }^{\mathrm{TH}}$ WEEK & $3.2 \pm 0.42$ & $0.50 \pm 1.03$ & $1.25 \pm 0.22$ & $0.97 \pm 0.50$ & $5.55 \pm 2.55$ \\
\hline & AT12 ${ }^{\mathrm{TH}}$ WEEK & $3.2 \pm 0.23$ & $0.43 \pm 0.55$ & $0.99 \pm 0.12$ & $0.93 \pm 0.60$ & $4.25 \pm 3.22$ \\
\hline \multirow{4}{*}{$\begin{array}{c}\text { Group } \\
\mathbf{3}\end{array}$} & BASELINE & $3.4 \pm 0.96$ & $2.85 \pm 0.88$ & $2.00 \pm 0.86$ & $1.18 \pm 0.44$ & $9.01 \pm 2.01$ \\
\hline & AT4 ${ }^{\mathrm{TH}}$ WEEK & $3.3 \pm 0.55$ & $1.80 \pm 0.66$ & $1.98 \pm 0.78$ & $1.02 \pm 0.76$ & $5.80 \pm 2.85$ \\
\hline & AT6 $^{\text {TH }}$ WEEK & $3.1 \pm 0.28$ & $1.00 \pm 1.02$ & $1.85 \pm 0.52$ & $0.71 \pm 0.53$ & $4.11 \pm 3.05$ \\
\hline & AT12 ${ }^{\mathrm{TH}}$ WEEK & $3.2 \pm 0.22$ & $0.75 \pm 1.03$ & $1.81 \pm 0.95$ & $0.78 \pm 0.52$ & $2.90 \pm 2.98$ \\
\hline
\end{tabular}

Table 2 is representing the clinical parametric values obtained by the clinical by following the standardized pressure. The probing depth value in group 1 varies from $3.3,3.2,3.3$, and3.2 from baseline to $4^{\text {th }}$ week to $6^{\text {th }}$ week till $12^{\text {th }}$ week. In group 2 the values came out to be 3.3, 3.1, 3.2, 3.2 at various week time period. In group 3 values ranged from 3.4, 3.3, 3.1 and 3.2.

Similar results were found in bleeding on probing with values in group 1 $(2.50,1.00,0.75,0.49)$; group $2(2.15,1.05$, $0.50,0.43)$; and group $3(2.85,1.80,1.00$, $0.75)$ at baseline, $4^{\text {th }}, 6^{\text {th }}$ and $12^{\text {th }}$ week respectively. 
Kousain Sehar. To evaluate the efficacy of adjuncts mouthwash along with oral hygiene habits in reduction of peri-implant mucositis- a randomized controlled trial

Group $1(1.25,0.98, .072,0.52)$; group $2(1.52,1.35,1.25,0.99)$ and group 3 $(2.00,1.98,1.85,1.81)$ values of modified gingival index at baseline, $4^{\text {th }}, 6^{\text {th }}$ and $12^{\text {th }}$ week.

On examining modified plaque index at baseline, $4^{\text {th }}, 6^{\text {th }}$ and $12^{\text {th }}$ week were found as in group $1(1.27,1.05,0.90$, and $0.78)$; group $2(1.52,1.35,1.25$, and 0.99$)$ and in group 3 as $(1.18,1.02,0.71$, and 0.78 ) respectively.

In case of mucositis severity score the value came out to be as group 1(9.08, $5.30,4.54,2.11)$ in group $2(9.08,6.50$, $5.55,4.25)$ and in group 3 as $(9.01,5.80$, 4.11, and2.90) at their respective weeks time.

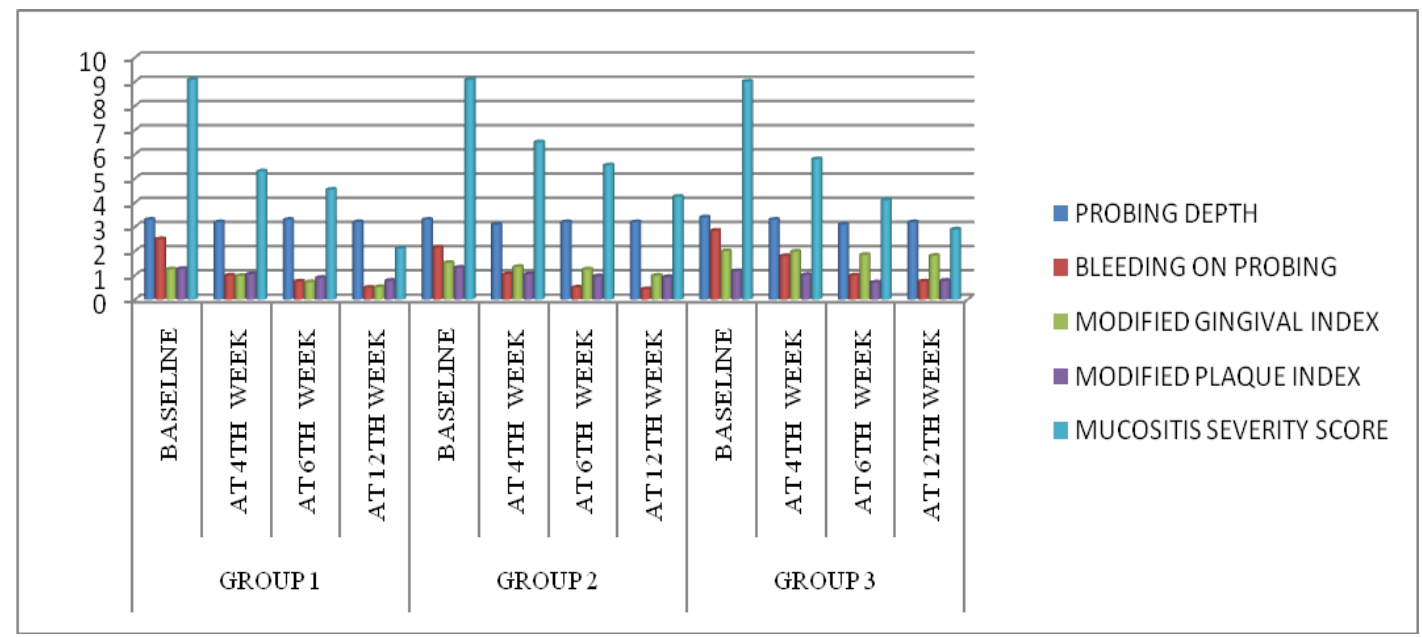

\begin{tabular}{|c|c|c|c|c|c|c|}
\hline Groups & Time Duration & $\begin{array}{c}\text { Probing } \\
\text { Depth }\end{array}$ & $\begin{array}{l}\text { Bleeding on } \\
\text { Probing }\end{array}$ & $\begin{array}{l}\text { Modified Gingival } \\
\text { Index }\end{array}$ & $\begin{array}{c}\text { Modified Plaque } \\
\text { Index }\end{array}$ & $\begin{array}{l}\text { Mucositis Severity } \\
\text { Score }\end{array}$ \\
\hline \multirow{3}{*}{$\begin{array}{c}\text { Group } \\
1\end{array}$} & AT $4^{\mathrm{TH}}$ WEEK & $-0.1 \pm 0.21$ & $-1.15 \pm 0.89$ & $-0.22 \pm 0.22$ & $-0.22 \pm 0.70$ & $-3.78 \pm 3.68$ \\
\hline & AT $6^{\mathrm{TH}}$ WEEK & $0 \pm 0.19$ & $-1.75 \pm 1.20$ & $-0.37 \pm 0.35$ & $-0.37 \pm 0.75$ & $-4.54 \pm 3.98$ \\
\hline & AT12 ${ }^{\mathrm{TH}}$ WEEK & $-0.1 \pm 1.0$ & $-2.01 \pm 1.00$ & $-0.49 \pm 0.15$ & $-0.49 \pm 0.69$ & $-6.97 \pm 2.59$ \\
\hline \multirow{3}{*}{$\begin{array}{c}\text { Group } \\
2\end{array}$} & AT $4^{\mathrm{TH}}$ WEEK & $-0.2 \pm 0.61$ & $-1.1 \pm 2.00$ & $-0.27 \pm 0.58$ & $-0.27 \pm 0.50$ & $-2.58 \pm 2.08$ \\
\hline & AT $6^{\mathrm{TH}}$ WEEK & $-0.1 \pm 0.43$ & $-1.65 \pm 1.08$ & $-0.35 \pm 0.23$ & $-0.35 \pm 0.75$ & $-3.53 \pm 2.99$ \\
\hline & AT12 ${ }^{\mathrm{TH}}$ WEEK & $-0.1 \pm 0.21$ & $-1.72 \pm 0.89$ & $-0.39 \pm 0.15$ & $-0.39 \pm 0.55$ & $-4.83 \pm 3.45$ \\
\hline \multirow{3}{*}{$\begin{array}{c}\text { Group } \\
\mathbf{3}\end{array}$} & AT $4^{\mathrm{TH}}$ WEEK & $-0.1 \pm 0.842$ & $-1.05 \pm 0.99$ & $-0.16 \pm 0.85$ & $-0.16 \pm 0.80$ & $-3.21 \pm 3.00$ \\
\hline & AT $6^{\mathrm{TH}}$ WEEK & $-0.3 \pm 0.18$ & $-1.85 \pm 1.09$ & $-0.47 \pm 0.65$ & $-0.47 \pm 0.62$ & $-4.9 \pm 3.09$ \\
\hline & AT12 ${ }^{\mathrm{TH}}$ WEEK & $-0.2 \pm 0.11$ & $-2.1 \pm 1.08$ & $-0.4 \pm 0.85$ & $-0.4 \pm 0.89$ & $-6.11 \pm 3.01$ \\
\hline
\end{tabular}

Table 3 represents the mean change from baseline to $4^{\text {th }}, 6^{\text {th }}$ and $12^{\text {th }}$ week. A negative value indicated a decrease in all the clinical parameters with maximum decrease in group 1 followed by 2 and then 3 . This clearly indicates that chlorhexidine remain as a gold standard in decreasing the diseased periodontal conditions in any individual including patients with implants.

Table 4: Results of Linear Regression Model for Periodontal Index Score

\begin{tabular}{|l|c|cc|c|}
\hline Contrast Estimates & Estimate & Confidence Interval (95\%) & P-Value \\
\hline Chx Irrigation Vs Herbal Only & -0.01 & -0.37 & 0.35 & 0.95 \\
\hline Chx Irrigation Vs Water Irrigation & 0.01 & -0.35 & 0.36 & 0.97 \\
\hline Water Irrigation Vs Instructions Only & -0.02 & -0.40 & 0.34 & 0.90 \\
\hline mPI score & 0.05 & -0.15 & 0.26 & 0.01 \\
\hline
\end{tabular}

Table 3 represents the reduction of average mPI over study period. The highest mean decrease of average mPI from baseline to final examination was observed in group 1; however, the scores of group2 and 3 were found to be very close. The results of the linear regression for mPI showed no significant influence of the three interventions $(p=.99)$ on the outcome (Table 4). Change of mPI rather seems to be highly dependent upon mPI measured at baseline $(p=.01)$. 
Kousain Sehar. To evaluate the efficacy of adjuncts mouthwash along with oral hygiene habits in reduction of peri-implant mucositis- a randomized controlled trial

Table 5: Results of Linear Regression Model for Bleeding on Probing

\begin{tabular}{|l|c|cc|c|}
\hline \multicolumn{1}{|c|}{ Contrast Estimates } & Estimate & Confidence Interval (95\%) & P-Value \\
\hline Chx Irrigation Vs Herbal Only & -0.7 & -0.28 & -0.26 & 0.02 \\
\hline Chx Irrigation Vs Water Irrigation & 0.29 & -0.8 & 0.10 & 0.13 \\
\hline Water Irrigation Vs Instructions Only & -0.31 & -0.82 & 0.12 & 0.10 \\
\hline mBOP score & 0.06 & -0.15 & 0.25 & 0.01 \\
\hline
\end{tabular}

Significant correlation between the intervention and BOP-positive sites $(p=.01)$ was found using the linear regression models. Estimates of BOP-positive sites for the pair wise contrasts between the groups are shown in Table 5.

\section{DISCUSSION}

The main aim of the study was to investigate the efficacy of three mouth washes in addition to mechanical plaque removal in clinics for the reduction of perimucositis over the period of 12 weeks. Two groups using chlorhexidine and herbal mouth wash were compared with the group that was given water as a substituent. The result of the study revealed that all the participants showed reduced sign of mucositis. The reduction of mucositis was significantly higher in group 1 using chlorhexidine compared to group 3 who used water. No significant effects in the reduction of severity of periimplantitis were found when compared with Clohex and herbal mouthwash with control group. Almost half of the population of the study had complete resolution of mucositis which was supported Salvi and Ramseier 2015 study revealing that complete resolution of mucositis is possible. ${ }^{16}$ Studies focused on the antibacterial effect of the mouthwash which decreased the inflammatory process of mucosa. Although prolong use could cause tooth staining, staining of mucosa and tongue, hypersensitivity, dryness and allergic reactions. Still chlorhexidine is used increasingly in clinical practice due to its high antimicrobial effects. ${ }^{17,18}$

The drawn out impact of antimicrobial mouthwash on peri-implant diseases has not been completely explained until today. A meta-examination of Cardona et al. revealed that Chlorhexidine isn't altogether viable in lessening the severity and frequency of oral mucositis. ${ }^{19}$
On the other hand, Pulcini et al. $(2019)^{20}$ exhibited the drawn out adjunctive impact of the everyday utilization of a $0.03 \%$ Chlorhexidine mouthwash and, demonstrated more prominent decrease in BOP, when contrasted with $0.05 \%$ cetylpyridinium chloride mouth wash in implant.

A huge decrease of BOP and Plaque Index through the application of a $0.12 \%$ chlorhexidine mouthwash was additionally introduced by Pena et al. (2019). ${ }^{21}$ Rohrer et al. (2010) thought about the antimicrobial viability of oral cleaning agents and appeared, that Octenidine and polyhexamethylene biguanide have comparative germicide impacts and can be considered as proportional choices for chlorhexidine. Anyway no prevalence over chlorhexidine could be found. ${ }^{22}$

A noteworthy decrease of Modified Gingival Index and Bleeding Index (MGI, BI) from utilizing an oral irrigator with $0.06 \%$ chlorhexidine contrasted with mouthwash with $0.12 \%$ chlorhexidine arrangement was likewise detailed. ${ }^{23}$ Menezes et al assessed the impact of essential periodontal treatment in blend with $0.12 \%$ chlorhexidine mouthwash and indicated that the CHX mouthwash was not more successful than the fake treatment in peri-implant mucositis treatment. ${ }^{24}$

The precise estimation of a low mucositis severity score for forestalling movement of peri-embed mucositis to periimplantitis might be examined in future examination and add to create customized techniques to forestall and treat peri-embed mucositis. ${ }^{15}$

\section{CONCLUSION}

Thinking about the limitations found in the current investigation, the adjuvant utilization of a mouthwash especially Clohex along with mechanical biofilm 
Kousain Sehar. To evaluate the efficacy of adjuncts mouthwash along with oral hygiene habits in reduction of peri-implant mucositis- a randomized controlled trial

removal can lessen the severity and prevalence of peri-implant mucositis following 12 weeks.

\section{Acknowledgement: None}

\section{Conflict of Interest: None}

\section{Source of Funding: None}

\section{Ethical Approval: Approved}

\section{REFERENCES}

1. Papathanasiou, E., Finkelman, M., Hanley, J., \&Parashis, A. O. (2016). Prevalence, etiology and treatment of peri-implant mucositis and peri-implantitis: A survey of periodontists in the United States. Journal of Periodontology, 87(5), 493-501. https://doi.org/10.1902/ jop.2015.150476

2. Heitz-Mayfield, L. J. A., \& Salvi, G. E. (2018). Peri-implant mucositis. Journal of Periodontology, 89(Suppl 1), S257-S266. https://doi.org/10.1002/JPER.16-0488

3. Heitz-Mayfield, L. J. A., \&Mombelli, A. (2014). The therapy of peri-implantitis: A systematic review. The International Journal of Oral \& Maxillofacial Implants, 29 (Suppl), 325-345. https://doi.org/ 10.11607/jomi.2014s uppl.g5.3

4. Schwarz, F., Derks, J., Monje, A., \& Wang, H.-L. (2018). Peri-implantitis. Journal of Clinical Periodontology, 45(Suppl 20), S246-S266. https://doi.org/10.1111/jcpe. 12954

5. Grischke, J., Eberhard, J., \&Stiesch, M. (2016). Antimicrobial dental implant functionalization strategies-A systematic review. Dental Materials Journal, 35(4), 545-558. https://doi.org/10.4012/ dmj.2015314

6. Dreyer, H., Grischke, J., Tiede, C., Eberhard, J., Schweitzer, A., Toikkanen, S. E., ... Stiesch, M. (2018). Epidemiology and risk factors of peri-implantitis: A systematic review. Journal of Periodontal Research, 53(5), 657-681. https://doi.org/10.1111/jre.12562

7. Daniel B, Michael E, Sebastian H, Jörg E, Meike S, Jasmin G. The effect of adjuvant oral irrigation on self-administered oral care in the management of peri-implant mucositis: A randomized controlled clinical trial. Clin Oral Impl Res. 2020;00:1-13. https://doi. org/10.1111/clr.13638.
8. Schwarz, F., \& Becker, J. (2016). Leitlinie PeriimplantäreInfektionen 2016. AWMF Online. Retrieved from https://www.dginet.de/docum ents/10164/ 15234 41/implperiim pllang.pdf/ae7c4 a5889c7-422d- 8339-1731e 68b8da6.

9. Daubert, D. M., \& Weinstein, B. F. (2019). Biofilm as a risk factor in implant treatment. Periodontology 2000, 81(1), 29-40. https://doi. org/10.1111/prd.12280.

10. Salvi, G. E., Aglietta, M., Eick, S., Sculean, A., Lang, N. P., \&Ramseier, C. A. (2012). Reversibility of experimental peri-implant mucositis compared with experimental gingivitis in humans. Clinical Oral Implants Research, 23(2), 182-190. https://doi.org/ 10.1111/j.1600-0501.2011.02220

11. Gomes, S. C., Corvello, P., Romagna, R., Müller, L. H., Angst, P. D. M., \& Oppermann, R. V. (2015). How do periimplant mucositis and gingivitis respond to supragingival biofilm control-An intraindividual longitudinal cohort study. European Journal of Oral Implantology, 8(1), 65-73.

12. Schwendicke, F., Tu, Y.-K., \&Stolpe, M. (2015). Preventing and treating periimplantitis: A cost-effectiveness analysis. Journal of Periodontology, 86(9), 10201029. https://doi.org/10.1902/jop.2015. 150071.

13. Löe, H. (1967). The Gingival Index, the Plaque Index and the Retention Index Systems. The Journal of Periodontology, 38(6), 610-616. https://doi.org/10.1902/ jop.1967.38.6.610.

14. Mombelli, A., van Oosten, M. A., Schurch, E., \& Land, N. P. (1987). The microbiota associated with successful or failing osseointegrated titanium implants. Oral Microbiology and Immunology, 2(4), 145151. https://doi.org/10.1111/j.1399-302X. 1987.tb002 98.

15. Grischke, J., Karch, A., Wenzlaff, A., Foitzik, M. M., Stiesch, M., \& Eberhard, J. (2019). Keratinized mucosa width is associated with severity of peri-implant mucositis. A cross-sectional study. Clinical Oral Implants Research, 30(5), 457-465. https://doi.org/10.1111/ clr.13432.

16. Salvi, G. E., \&Ramseier, C. A. (2015). Efficacy of patient-administered mechanical and/or chemical plaque control protocols in the management of peri-implant mucositis. A systematic review. Journal of Clinical 
Periodontology, 42 (Suppl 1 6), S 187-201. https://doi. org/10.1111/jcpe.12321.

17. Carinci, F., Lauritano, D., Bignozzi, C. A., Pazzi, D., Candotto, V., Santos de Oliveira, P., \& Scarano, A. (2019). A new strategy against peri-implantitis: Antibacterial internal coating. International Journal of Molecular $\quad$ Sciences, $20(16)$, https://doi.org/10.3390/ijms2 0163897

18. Chye, R. M. L., Perrotti, V., Piattelli, A., Iaculli, F., \& Quaranta, A. (2019). Effectiveness of different commercial chlorhexidine-based mouthwashes after periodontal and implant surgery: A systematic review. Implant Dentistry, 28(1), 74-85. https://doi.org/10.1097/ID.00000 00000000854

19. Cardona, A., Balouch, A., Abdul, M. M., Sedghizadeh, P. P., \&Enciso, R. (2017). Efficacy of chlorhexidine for the prevention and treatment of oral mucositis in cancer patients: A systematic review with metaanalyses. Journal of Oral Pathology \& Medicine: Official Publication of the International Association of Oral Pathologists and the American Academy of Oral Pathology, 46(9), 680-688. https://doi.org/10.1111/jop.12549

20. Pulcini, A., Bollaín, J., Sanz-Sánchez, I., Figuero, E., Alonso, B., Sanz, M., \& Herrera, D. (2019). Clinical effects of the adjunctive use of a $0.03 \%$ chlorhexidine and $0.05 \%$ cetylpyridinium chloride mouth rinse in the management of peri-implant diseases: A randomized clinical trial. Journal of Clinical Periodontology, 46, 342-353. https://doi. org/10.1111/jcpe.13088.
21. Peña, M., Barallat, L., Vilarrasa, J., Vicario, M., Violant, D., \&Nart, J. (2019). Evaluation of the effect of probiotics in the treatment of peri-implant mucositis: A triple-blind randomized clinical trial. Clinical Oral Investigations, 23(4), 16731683. https://doi.org/10.1007/s0078 4-0182578-8.

22. Rohrer, N., Widmer, A. F., Waltimo, T., Kulik, E. M., Weiger, R., Filipuzzi- Jenny, E., \& Walter, C. (2010). Antimicrobial efficacy of 3 oral antiseptics containing octenidine, polyhexamethylene biguanide, or Citroxx: Can chlorhexidine be replaced? Infection Control and Hospital Epidemiology, 31(7), 733-739. https://doi.org/10.1086/653822

23. Felo, A., Shibly, O., Ciancio, S. G., Lauciello, F. R., \& Ho, A. (1997). Effects of subgingival chlorhexidine irrigation on periimplant maintenance. American Journal of Dentistry, 10(2), 107-110.

24. Menezes, K. M., Fernandes-Costa, A. N., Silva-Neto, R. D., Calderon, P S., \&Gurgel, B. C. V. (2016). Efficacy of $0.12 \%$ chlorhexidine gluconate for non-surgical treatment of peri-implant mucositis. Journal of Periodontology, 87(11), 1305-1313. https://doi.org/10.1902/jop.2016.160144

How to cite this article: Kousain Sehar. To evaluate the efficacy of adjuncts mouthwash along with oral hygiene habits in reduction of peri-implant mucositis- a randomized controlled trial. International Journal of Science \& Healthcare Research. 2022; 7(1): 117-123. DOI: https://doi.org/10.52403/ijshr.20220120 